\title{
GAUSS-DIMAS - EXPERIMENTO PARA MEDIÇÃO DE CAMPO MAGNÉTICO APLICADO AO PROCESSO DE SEPARAÇÃO MAGNÉTICA EM PLANTA DE BENEFICIAMENTO DE MINÉRIO DE FERRO NA CIDADE DE ITABIRA-MG
}

\author{
Paulo H. V Soares ${ }^{1}$, Edson D. Silveira ${ }^{1}$, Rubens Guerra ${ }^{1}$, Alisson ZaCarias ${ }^{1}$, Robsons VIEIRA $^{1}$,Vicen- \\ TINO J. P. RODRIGUES ${ }^{1}$, GUSTAVO DiAS SOUZA ${ }^{2}$. \\ 1. Mina Conceição, Bloco IV, Serra do Esmeril, sn, Zona rural, Itabira - MG \\ 2. UNIFEI, campus Itabira, Rua Irmã Ivone Drumond, 200, Distrito Industrial II, Itabira-MG \\ E-mails: paulo.vieira.soares@vale.com, edson.silveria@vale.com, rubens.guerra@vale.com, alis- \\ son.zacarias@vale.com, robson.vieira@vale.com, vicentino.rodrigues@vale.com, dias.gustavo@out- \\ look.com
}

\begin{abstract}
It is known that one of the objectives of mining is to obtain a material with a high content of iron. However, with the continuous exploitation of the mines over time the useful material ends up depleting, in this way the content of contaminating material increases. From these facts one notices the necessity of the separation of the useful material from the reject, a widely used solution is the magnetic separation. For this separation to take place effectively, it is necessary to know the magnetic field present in the equipment that performs this separation, also known as Jones (magnetic separator). Due to the scarcity of an instrument for field measurement in real time, the same is inferred by the current value applied. However, this inference does not always portrays reality, since a coil may not have optimal working conditions, such as a variation in impedance, for example. For field measurements using a specific instrument, the magnetic separator needs to be blocked and stopped, and the measurement process must be performed offline (without material passing through the equipment). This process is costly, besides it provides only one point measurement. In this way an equipment was developed, there is able to carry out the field measurement in real time, online and sending this data to a PLC for treatment and analysis.
\end{abstract}

Keywords_ Iron ore, magnetic field, measurement, magnetic separator.

Resumo- Sabe-se que um dos objetivos da mineração é obter um material com alto teor de ferro. Entretanto, com a exploração contínua das minas, ao longo do tempo o material útil acaba exaurindo-se, deste modo o teor de material contaminante aumenta. A partir destes fatos percebe-se a necessidade da separação do material útil do rejeito, uma solução amplamente utilizada é a separação magnética. Para que esta separação ocorra de forma efetiva, necessita-se conhecer o campo magnético presente no equipamento que realiza tal função, sendo este conhecido como Jones (separador magnético). Devido à escassez de um instrumento para medição de campo magnético em tempo real, infere-se este campo pelo valor de corrente aplicada. Entretanto esta inferição nem sempre retrata a realidade, pois uma bobina pode não apresentar condições ideais de trabalho, como uma variação na impedância por exemplo. Para medidas pontuais de campo utilizando um instrumento específico para medição é necessário que o separador magnético se apresente bloqueado e parado, além do processo de medição ser realizado de forma offline (sem passagem de material pelo equipamento). Este processo pode ser custoso, além de apresentar apenas uma medição pontual. Deste modo desenvolveu-se um equipamento capaz de efetuar a medição de campo em tempo real, de forma online e enviando estes dados para um PLC para tratamento e análise.

Palavras-chave—Minério de ferro, campo magnético, medição, separador magnético.

\section{Introdução}

Se um condutor é enrolado em forma de uma espira simples e faz-se passar por ele uma corrente, é formado um campo magnético através deste elemento de bobina. Quando a corrente é desligada o campo magnético é também interrompido. Segundo PEM (2011), alguns sólidos são atraídos para um dos pólos do magneto enquanto outros sólidos são repelidos sob as mesmas circunstâncias. Assim, são conhecidas duas classes de materiais.

Para Fonseca (2012), o Concentrador Magnético a úmido de alta intensidade ou Jones é um equipamento que utiliza a propriedade magnética para fazer a separação das espécies minerais. As partículas magnéticas são atraídas pelo campo magnético formado pelas bobinas e formam o concentrado. Por outro lado, as não magnéticas são descartadas por arraste hidráulico e pela gravidade, formando o rejeito. As partículas mistas são descartadas (no médio) por ação entre forças competitivas.
Já para Lisboa (2014), a medida em que as minas de minério de ferro vão envelhecendo e a lavra vai avançando, é normal que os teores de elementos úteis diminuam e os de contaminantes aumentem. No caso da mina de Conceição isso não é diferente, o teor de SIO2 na fração $-1+0.15 \mathrm{~mm}$ do Itabirito que alimenta a concentração magnética, vem aumentando a cada ano e com isso o teor deste contaminante, que é indesejável no produto gerado após o processo de concentração magnética, também.

Hoje em Itabira, na mina de Conceição, os separadores magnéticos estão no processo a úmido e são diferenciados como Jones de Finos e Jones de Grossos. Basicamente os equipamentos são idênticos, porém são diferenciados pelas características físicas do minério que o alimenta. O Jones de Finos é alimentado por partícula $-0,15 \mathrm{~mm}$ e o Jones de Grossos é alimentado por partículas de $(-1,4 \mathrm{~mm}+0,15 \mathrm{~mm})$. 


\section{Separadores magnéticos de alta intensidade}

\subsection{Força sobre a partícula}

No processo de separação a úmido, a partículas de minerais, colocadas dentro do campo magnético, sofrem ação das seguintes forças: Força magnética; Força da gravidade; Força de arraste hidrodinâmico; Forças interpartículas.

A Figura 1 mostra o resultado da combinação destas forças, e da ação individual de cada uma delas na trajetória das partículas. As forças interpartículas, existentes entre as partículas magnéticas e as não magnéticas, são determinantes na qualidade da separação.

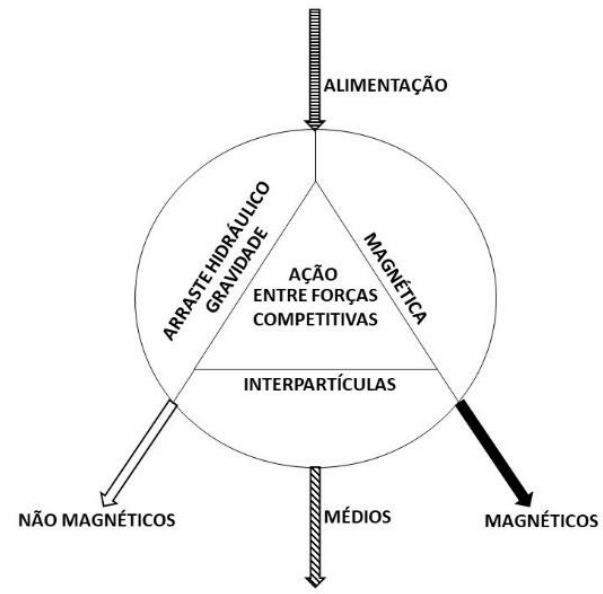

Figura 1. Ação das forças na separação magnética a úmido

\subsection{Campo magnético}

Sabe-se que a simetria não é suficiente para utilizar a lei de Ampère para determinar o campo magnético produzido por uma bobina percorrida por uma corrente. Logo recorre-se à lei de Biot-Savart. Deste modo calcula-se o campo em pontos situados na região central da bobina, a qual será chamado de eixo z. O módulo deste campo é calculado da seguinte forma na unidade Tesla.

$$
B(z)=\frac{N \mu_{0} i R^{2}}{2\left(R^{2}+Z^{2}\right)^{3 / 2}}(\hat{z})
$$

$\mu_{0}$ _ Permeabilidade magnética do vácuo

$\mathrm{N}$ Número de espiras da bobina

I Corrente na bobina

Z Distância em linha reta do ponto central da bobina até o ponto de interesse

$\mathrm{R}$ Raio das espiras da bobina

$\hat{z} \quad$ Direção do campo magnético

\subsection{Susceptibilidade magnética}

Susceptibilidade magnética é a propriedade inerente aos materiais que define sua resposta frente a um campo magnético. Os materiais ferromagnéticos são fortemente atraídos pelo campo magnético, os materiais paramagnéticos sofrem pouca influência, sendo fracamente atraídos pelo campo magnético e os materiais diamagnéticos são repelidos pelo campo magnético.

Conforme PEM (2011), a curva (a) de resposta rápida representa os minerais ferromagnéticos; $\mathrm{A}$ curva (b) com a mesma tendência, porém com menor intensidade, representa os minerais paramagnéticos; $\mathrm{E}$ a curva (c) repelidos pelo campo é de minerais diamagnéticos.

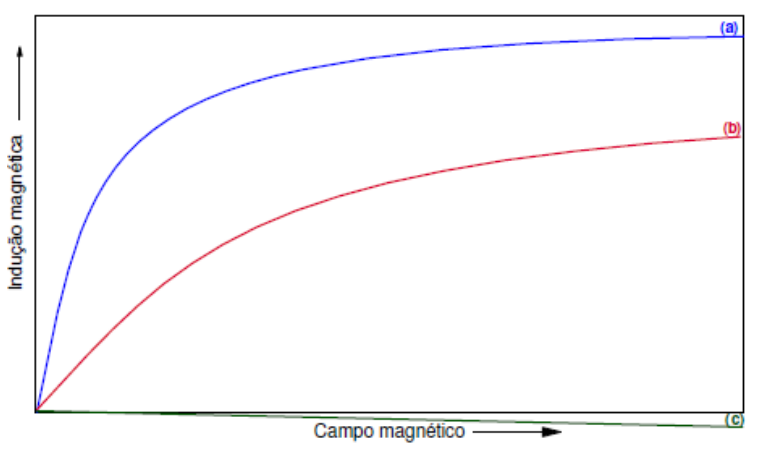

Figura 2. Resposta ao campo magnético

\subsection{Separadores magnéticos}

Conforme Gaustec (2017) os separadores magnéticos são compostos basicamente por: Caixa de alimentação (1); Caixa de pressão do médio (2); Caixa de lavagem de concentrado (3); Caixa rejeito (4); Bobina eletromagnética (5); Bloco por rotor (6); como mostra a Figura 3.

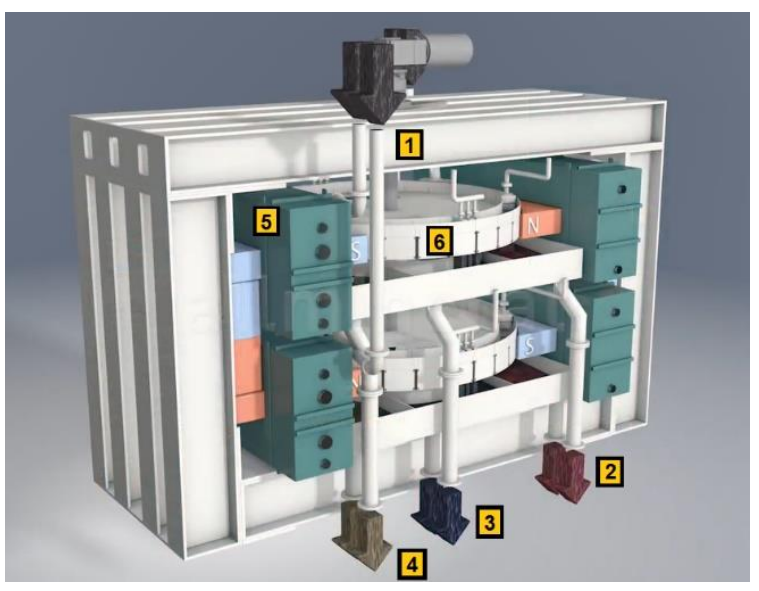

Figura 3. Estrutura física do separador magnético

\subsection{Circuito de potência}

A Figura 4 representa o circuito elétrico do Jones. O transformador $\mathrm{T} 1$ é alimentado em $440 \mathrm{~V}$ no primário e possui saída em $240 \mathrm{~V}$ no secundário, essa tensão alternada é transformada em tensão continua por meio de um retificador semicontrolado de 6 pulsos. 


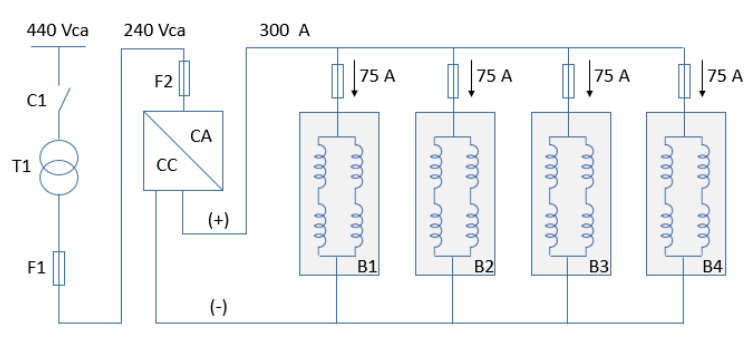

Figura 4. Circuito de potência do separador magnético

Para atender o critério de projeto na recuperação do material, o separador magnético deve fornecer em seu interior um campo de 9000 Gauss. Em condições normais, esse campo é obtido com uma corrente de $75 \mathrm{~A}$ por bobina, totalizando $300 \mathrm{~A}$ na saída do retificador.

\subsection{Circuito de controle}

Nos equipamentos convencionais, o controle da corrente é realizado utilizando um circuito de disparo de tiristores conforme Figura 5. A placa de disparo recebe a referência do PLC (Programmable Logic Controller) em 4 a 20 mA, converte para referência de tensão e dispara os semicondutores de potência.

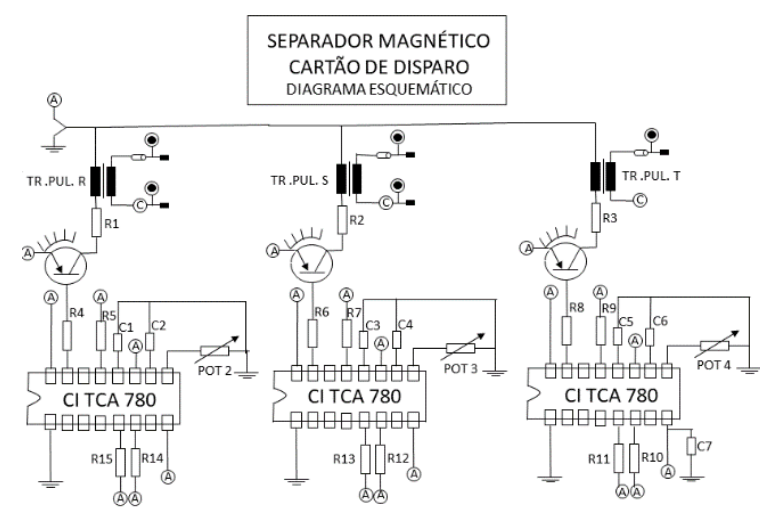

Figura 5. Circuito de controle do separador magnético

Para realimentar o processo, existe um resistor shunt na saída do retificador que é constantemente monitorado por um transdutor que, por sua vez, envia o sinal de feedback ao PLC.

\subsection{Controle de processo}

Para otimização do processo de separação magnética, se faz necessário conhecer o valor do campo magnético presente no equipamento. A função do Jones é realizar a separação magnética do minério de ferro da sílica. Para tal, o equipamento trabalha com ajuste de corrente próximo a 300 A e se espera um campo magnético no centro próximo de 9000 Gauss.

Devido à falta de um instrumento para medição de campo online, o equipamento trabalha por meio de inferência, utilizando o valor de corrente, que nem sempre retrata o valor real da variável. Caso uma bobina não esteja na condição ideal de trabalho, apre- sente variações na sua impedância ou até mesmo venha a queima (impedância $\rightarrow \infty$ ), a performance do equipamento será comprometida.

\section{Trabalho de melhorias}

\subsection{Medição de temperatura}

Visando melhorar o sistema de refrigeração das bobinas, a equipe de engenharia conduziu o estudo e aquisição de novas bobinas conforme Figura 6. O trabalho foi voltado para eficiência do sistema de ventilação (1), facilidade na troca dos ventiladores (2) e monitoramento da temperatura através de sensores PT100 (3).

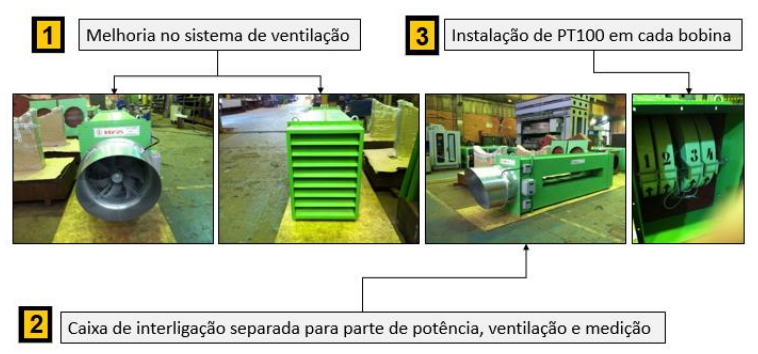

Figura 6. Melhorias realizadas nas bobinas do separador magnético

\subsection{Medição de campo}

Para realização da medição de campo, quando é necessário verificar a eficiência do Jones, é utilizado, pela equipe de operação, um equipamento portátil chamado Gaussmeter. O processo consiste em realizar o bloqueio da parte girante (rotor) do equipamento na subestação e na sequência realizar a medição do campo no centro do separador magnético.

Este processo somente pode ser realizado com o equipamento parado e bloqueado, demanda a utilização de equipamento específico de medição e é realizado de forma offline (sem a passagem de material pelo separador magnético).

Idealizado no final de 2015 por Edson Dimas da Silveira, o medidor de campo baseado no princípio da célula de carga teve seu primeiro experimento no mesmo ano. A Figura 7 ilustra a solução.

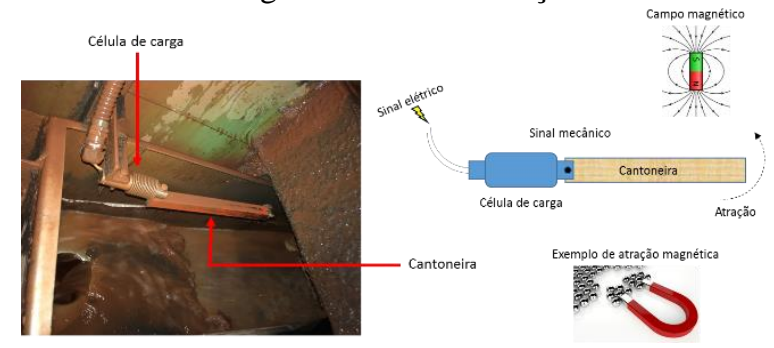

Figura 7. Princípio de medição usando celular de carga

O teste piloto para realização da medição do campo magnético utilizando células de carga foi realizado no final de 2015 no separador magnético 6408. Foram montadas as células de carga, transdutores para 
tratamento do sinal e realizada a interligação via cabo 4 a $20 \mathrm{~mA}$ com o PLC.

Como consequência de um baixo isolamento nas bobinas, foi necessário realizar a troca das bobinas avariadas por bobinas novas. Durante o período de troca, os sensores foram desativados conforme Figura 8.

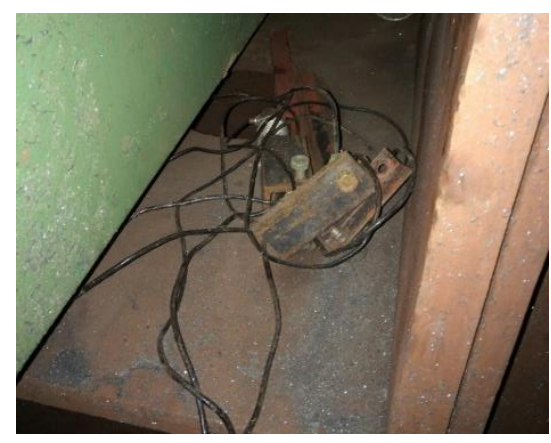

Figura 8. Sensor desativados

Devido às necessidades operacionais, os separadores magnéticos não foram demandados até o segundo semestre de 2017, quando começaram a entrar em operação novamente.

\subsection{Painel de campo}

Para melhorar o monitoramento dos sinais, foi especificado um painel que possibilita a aquisição e monitoramento dos sinais de temperatura e campo dos equipamentos. Os painéis contam com um concentrador de sinais, dispositivo para bloqueio e indicação local do campo magnético.

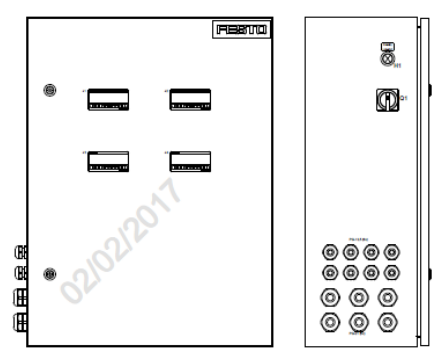

Figura 8. Painel de campo

A Figura 9 mostra a estrutura de rede montada e os equipamentos necessários para interligação entre a área dos Jones e o PLC.

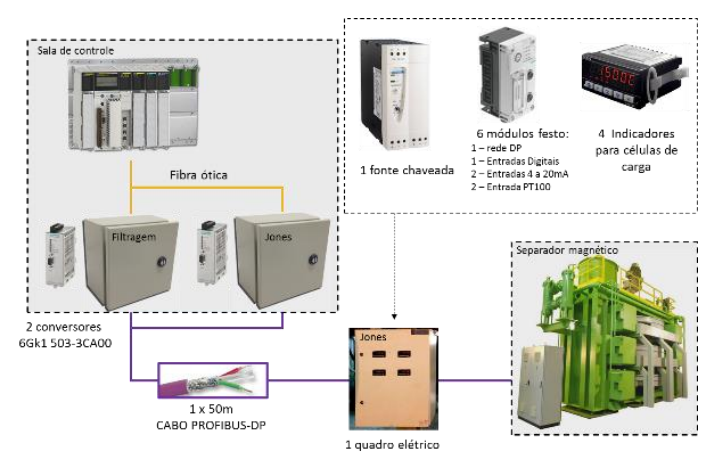

Figura 9. Estrutura de rede

\subsection{Separador magnético 6403}

O painel foi instalado no SM6403, pois este equipamento possuía 4 bobinas novas. Outro fator se refere aos ventiladores e caixa de proteção das bobinas, que possuem modelos diferentes, conforme pode ser observado na Figura 10, possibilitando uma análise comparativa entre elas.

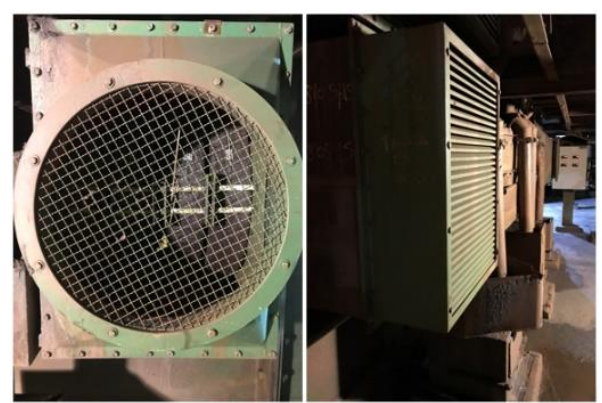

Figura 10. Sistema de ventilação do SM6403

Foram instaladas 3 células de carga e 1 micro célula conforme Figura 11.

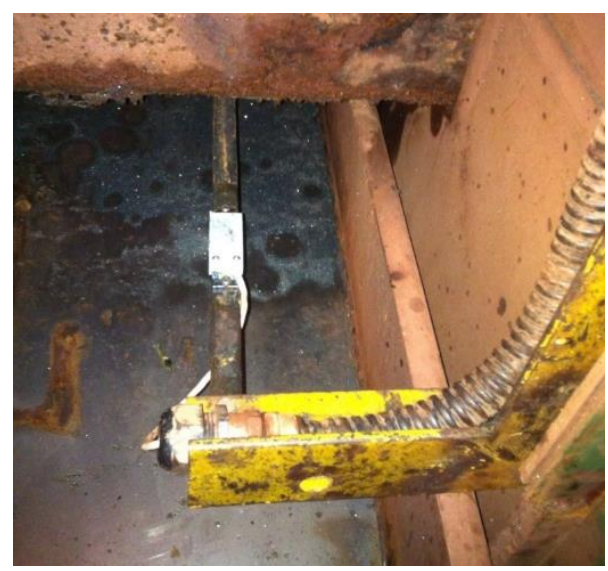

Figura 11. Micro célula instalada no SM6403

Cada célula de carga foi interligada em um controlador presente na porta do painel conforme Figura 12.

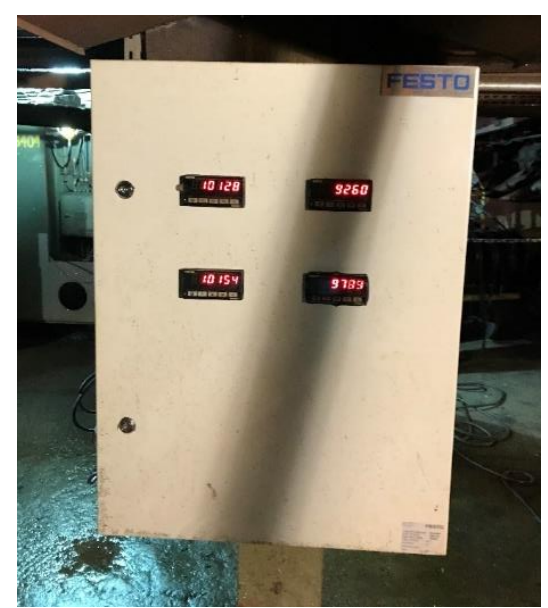

Figura 12. Estrutura de rede 
Os sensores PT100 a 3 fios também foram interligados no mesmo painel e o valor de temperatura enviado via rede de comunicação até o PLC.

\section{Resultados}

\subsection{Experimento no separador magnético 6403}

Para realização dos testes foi utilizado o GAUSSMETER TLMP-HALL. O rotor do separador magnético foi bloqueado e na sequência a ponta do GAUSSMETER inserida no centro da placa conforme Figura 13.

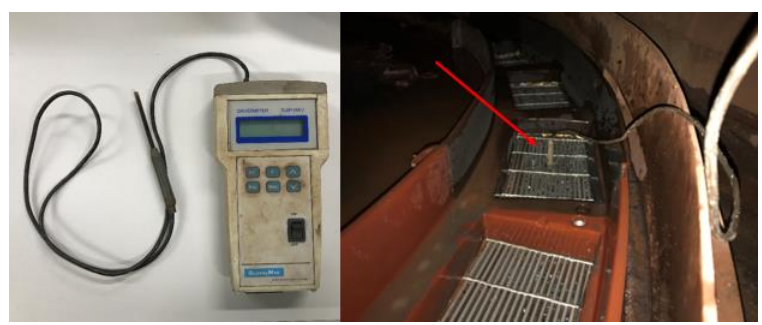

Figura 13. Medição de campo no rotor inferior

Inicialmente foram realizados testes nas bobinas superior e inferior do equipamento, porém na sequência prosseguiu-se os testes apenas na parte superior, pois demandava um menor esforço físico nas medições.

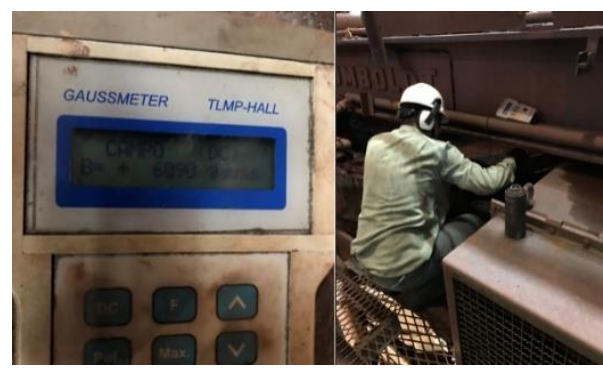

Figura 13. Medição de campo no rotor superior

A Figura 14 ilustra os pontos de medição (de A a H). As bobinas 1 e 2 pertencem ao rotor superior e as bobinas 3 e 4 ao rotor inferior.

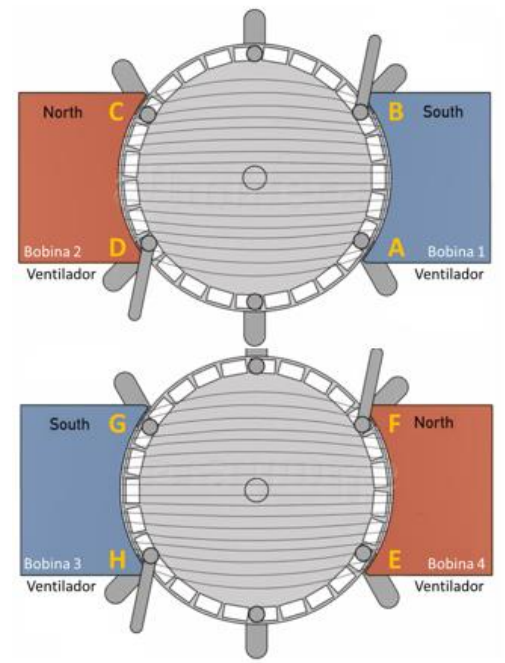

Figura 14. Pontos de medição
Foram realizadas 36 medições, com intensidade de corrente entre 50 A e 212 A. A Figura 15 ilustra os resultados para o rotor inferiror (de A a D). Nota-se que mesmo para valores iguais de corrente, o valor do campo apresentou resultados diferentes. Isso se deve ao posicionamento da ponta (sonda) do instrumento na placa. Sempre que era retornado ao ponto de medição, não se conseguia o mesmo posicionamento.

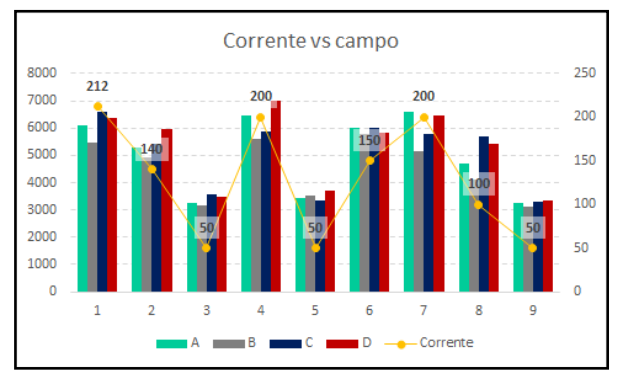

Figura 15. Resultado das medições

Visando mitigar a influência da posição da ponta do sensor, os testes no ponto A e $\mathrm{C}$ foram realizados com o instrumento fixo e de forma sequencial. A Figura 16 apresenta os resultados.

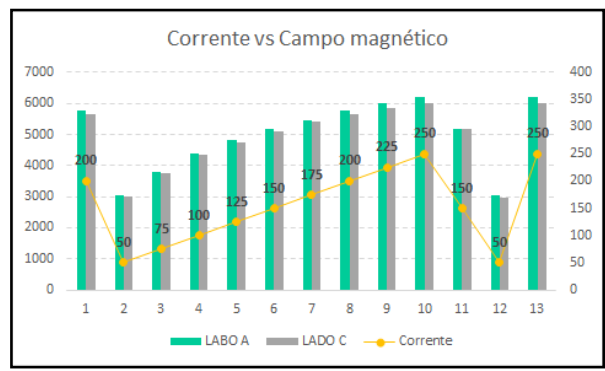

Figura 16. Resultado das medições - Ponto A e C (sonda fixa)

Utilizando os pontos obtidos nas medições é possível adicionar uma linha de tendência e extrair uma função polinomial do gráfico conforme Figura 17.

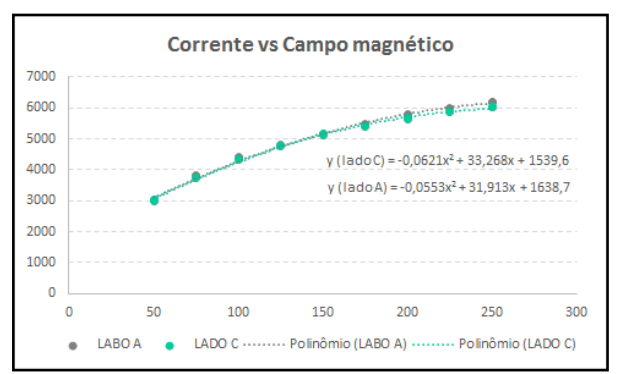

Figura 17. Linha de tendência

A Figura 18 ilustra o campo medido pelo GAUSS-DIMAS (nome dado ao instrumento em homenagem ao seu inventor Edson Dimas da Silveira) em resposta à corrente para 5731 pontos gravados no historiador durante os testes. Na parte superior é apresentado o comportamento do campo das quatro bobinas em resposta ao valor de corrente (sendo a corrente apresentada na parte inferior da figura). 


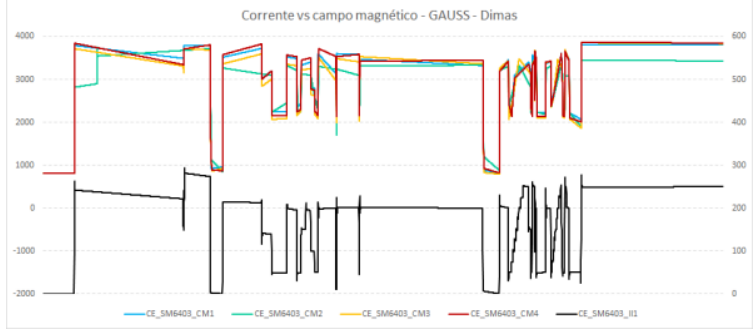

Figura 18. Corrente vs campo magnético medido pelo GAUSS-DIMAS

Na figura 19 tem-se a representação do campo magnético das 4 bobinas por meio do gráfico de dispersão.

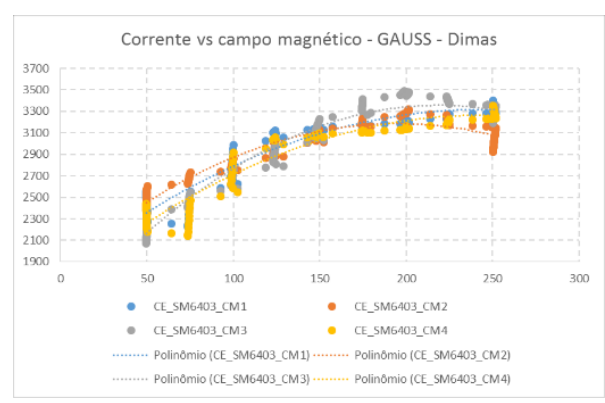

Figura 19. Resultado das medições

As Figuras 20 a 23 ilustram os valores de corrente versus campo, apresentam a função da linha de tendência e a correlação $\left(R^{2}\right)$, de cada bobina. Os valores levam em consideração todos os pontos apresentados na Figura 18. Destaca-se que, entre os resultados obtidos, os valores mostrados na Figura 22 apresentam correlação de $94 \%$.

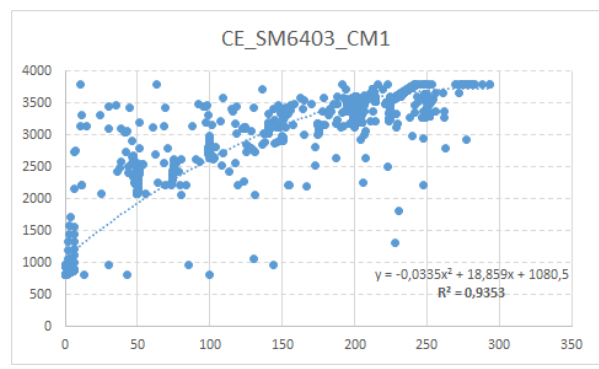

Figura 20. Resultado das medições - Bobina 01

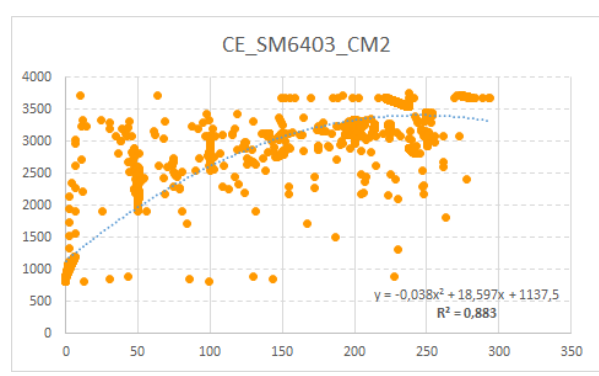

Figura 21. Resultado das medições - Bobina 02

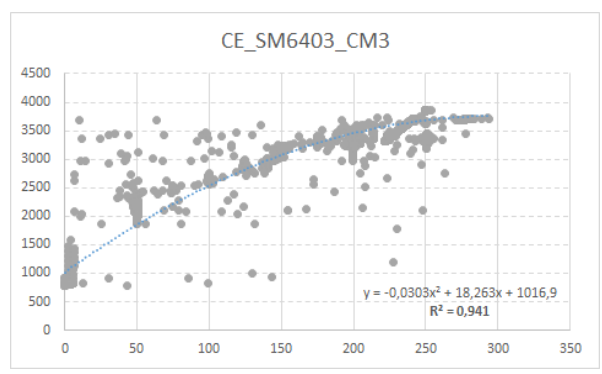

Figura 22. Resultado das medições - Bobina 03

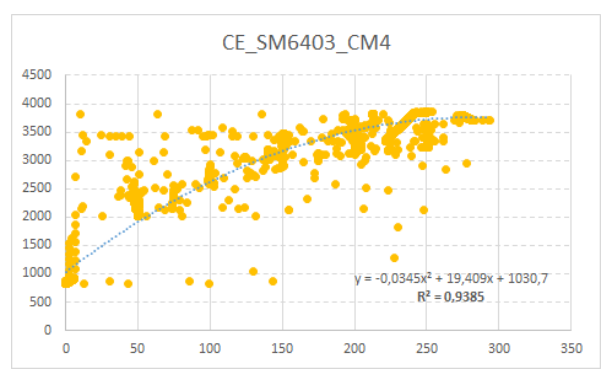

Figura 23. Resultado das medições - Bobina 04

Adicionalmente ao teste de campo, foi criado no PLC os tags de temperatura e uma lógica para proteção das bobinas. Esta emite um alarme em $105^{\circ} \mathrm{C}$ e desliga o equipamento caso o valor de temperatura seja superior a $120^{\circ} \mathrm{C}$.

\section{Conclusão}

Os resultados apresentados pelo GAUSS-DIMAS são interessantes e sobre o $\mathrm{n}^{\circ}$ BR.10.2018.012398.0 foi depositado o pedido de patente no Instituto Nacional da Propriedade Industrial.

Concluímos que as correlações entre corrente e campo medidos pelo GAUS-DIMAS são significativas, pois estão entre $88 \%$, para o pior caso, e $94 \%$, para o melhor resultado no SM6403. Como os dados foram historiados "puros", sem escalonamento, é necessário definir o mínimo e o máximo no PLC com base nos valores medidos pelo GAUSSMETER.

A próxima etapa para o SM6403 é a realização do teste de ferro no rejeito, possibilitando associar esse indicador com o campo medido pelo GAUSS-DIMAS. Ao final, será proposto a troca do input do operador no supervisório de processo, que deixará de solicitar o setponit em corrente e passará a solicitar o mesmo em campo magnético.

\section{Referências Bibliográficas}

PEM - Programa de Especialização em Mineração Vale (2011). Separação granítica e magnética.

Fonseca, A; Jesus, W; Tonelli, F; (2012). Workshop Operacional. Jones Usina de Tratamento Conceição.

Lisboa, A; Tonelli, F; Vieira, R; Oliveira, R. (2014). Trabalho de 6 sigma, Aumento do fator de enriquecimento do Sinter feed 3 - CE.

Gaustec (2017). Separador magnético WHIMS. 